\title{
An improved troposphere tomographic approach considering the signals coming from the side face of the tomographic area
}

\author{
Qingzhi Zhao ${ }^{1}$ and Yibin Yao ${ }^{1,2,3}$ \\ ${ }^{1}$ School of Geodesy and Geomatics, Wuhan University, Wuhan, China \\ ${ }^{2}$ Key Laboratory of Geospace Environment and Geodesy, Ministry of Education, Wuhan University, Wuhan, China \\ ${ }^{3}$ Collaborative Innovation Center for Geospatial Technology, Wuhan, China \\ Correspondence to: Yibin Yao (ybyao@whu.edu.cn)
}

Received: 19 October 2016 - Revised: 8 December 2016 - Accepted: 8 December 2016 - Published: 11 January 2017

\begin{abstract}
The spatio-temporal distribution of atmospheric water vapour information plays a crucial role in the establishment of modern numerical weather forecast models and description of the different weather variations. A troposphere tomographic method has been proposed considering the signal rays penetrating from the side of the area of interest to solve the problem of the low utilisation rate of global navigation satellite system (GNSS) observations. Given the method above needs the establishment of a unit scale factor model using the radiosonde data at only one location in the research area, an improved approach is proposed by considering the reasonability of modelling data and the diversity of the modelling parameters for building a more accurate unit scale factor model. The new established model is established using grid point data derived from the European Centre for Medium-Range Weather Forecasts (ECMWF) and evenly distributed in the tomographic area, which can enhance the number of calculated initial water vapour density values with high accuracy. We validated the improved method with respect to the previous methods, as well as the result from a radiosonde using data from 12 stations from the Hong Kong Satellite Positioning Reference Station Network. The obtained result shows that the number of initial values estimated by the new model is increased by $6.83 \%$, while the internal and external accuracies are 0.08 and $0.24 \mathrm{~g} \mathrm{~m}^{-3}$, respectively. Integrated water vapour (IWV) and water vapour density profile comparisons show that the improved method is superior to previous studies in terms of RMS, MAE, and bias, which suggests higher accuracy and reliability.
\end{abstract}

Keywords. Hydrology (water supply)

\section{Introduction}

Atmospheric water vapour only accounts for a small proportion of total atmospheric volume, but it plays an important role in the formation of clouds and rainfall, as well as the evolution of weather systems (Liu et al., 2005; Wang et al., 2014). Knowing precise information about the spatiotemporal distribution of water vapour is a prerequisite for atmospheric research (Emanuel et al., 1995; Park et al., 1999; Bauer et al., 2011; Ducroco et al., 2002). With the rapid development of the global navigation satellite system (GNSS), the GNSS troposphere tomographic technique has become a potentially powerful method for obtaining three-dimensional distributions of water vapour with high spatio-temporal resolution (Braun, et al., 1999; Flores et al., 2000; Troller, et al., 2002; Nilsson and Gradinarsky, 2006; Perler et al., 2011; Brenot et al., 2014; Yao and Zhao, 2016). In recent years, the integration of GNSS data and NWP has given better results in the field of GNSS meteorology (Douša and Václavovic, 2014; Douša et al., 2016; Wilgan et al., 2016).

The concept of tropospheric tomography was first proposed with the use of low-cost L1 observations (Braun et al., 1999) and realised by Flores et al. (2000) with GPS dualfrequency observations, which marks the beginning of tomographic techniques for GNSS and its applications to meteorology. Tropospheric tomography is used to discretise the tomographic area into a large number of voxels and established the integral equation using the signal observations which cross the whole tomographic area (Flores et al., 2000). In addition, some constraint conditions are also imposed on the tomographic modelling so as to overcome the ill-posed problem caused by the unfavourable geometric distribution 
of ground-based receivers as well as the constellation of the GNSS satellites (Flores et al., 2000; Skone and Houle, 2005; Nilsson and Gradinarsky, 2006; Bender and Raabe, 2007; Brenot et al., 2014). Recently, some external information was exploited which tries to improve the initial fields used in tomographic modelling. The initial water vapour fields calculated from COSMIC radio occultation data were used as initial values to enhance the accuracy of iterative algorithms (Xia et al., 2013). Several studies also verified that the performance of tomographic results has been improved by superimposing the 2-D images of integrated water vapour (IWV) derived from interferometric synthetic aperture radar (InSAR) (Heublein et al., 2015; Benevides et al., 2015); however, only the observed signal rays penetrating from the top boundary of the area of interest were used to build the observation equation in previous studies for the most previous studies. Notarpietro et al. (2011) propose a method to calculate the value of signal slant water vapour (SWV) outside the tomographic area with ECMWF data, while Benevides et al. (2014) propose the geometric linear method using the empirically exponential negative function. Chen and Liu (2016) estimate the slant wet delay (SWD) outside the modelling area with the help of numerical weather prediction (NWP) profile data. Yao et al. (2016) proposed a method which also considers the signals penetrating from the side face of the research area by introducing the unit scale factor model, while the unit scale factor refers to the proportion between the value of signal SWV inside the tomographic area and the total value of this signal SWV. This method proposed above enhanced the utilisation rate of signal observations as well as the number of voxels crossed by satellite rays. To improve the accuracy of the method proposed above, a more sophisticated unit scale factor model is reconstructed from the point of selection of modelling data and modelling parameters. The experimental results show that the tomographic result using the new unit scale factor model is superior to those methods outlined in previous studies.

\section{An improved method for tropospheric tomography}

In this section, an improved method of using the signals penetrating from the side face of the area of interest was introduced. According to a previous study (Yao et al., 2016), the values of the unit scale factor of each voxel in every layer was first calculated using existing radiosonde data in the first 3 days of the tomographic epoch and SWV signals penetrating from the top of research area. As shown by the green voxels in Fig. 1, the unit scale factor of each voxel for the location of the radiosonde station was calculated based on the formula

$\gamma_{p}^{k}=\frac{\rho_{i j k}^{0}}{\mathrm{SWV}^{p}}$,

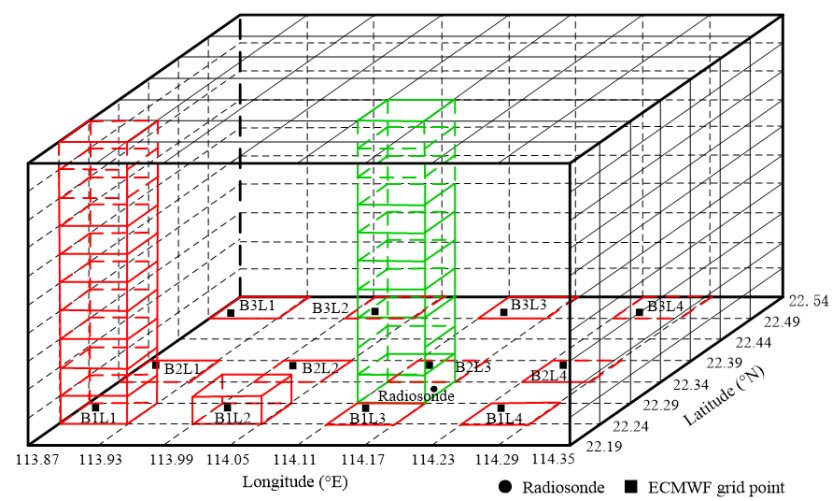

Figure 1. Schematic of the improved method for building the unit scale factor model.

where $\gamma_{p}^{k}$ is the unit scale factor of the $k$ th layer for signal $p$, $\rho_{i j k}^{0}$ represents the initial water vapour value calculated using radiosonde data in the first three days of the tomographic epoch, and $\mathrm{SWV}^{p}$ is the total slant water vapour content of ray $p$. Then, the unit scale factor model of every voxel for the location of the radiosonde station can be expressed and regarded as thus establishing the model as the new representation of the whole layer:

$\gamma_{\mathrm{ele}}^{k}=a_{1}^{k}+a_{2}^{k} \cdot \sin (\mathrm{ele})$,

where $\gamma_{\text {ele }}^{k}$ is the established unit scale factor model for the $k$ th layer based on the data calculated in Eq. (1); $a_{1}$ and $a_{2}$ are the coefficients of the unit scale factor model, which are estimated by the least squares method; and "ele" denotes the elevation angle of the signal ray. Finally, the average initial water vapour density value of voxels in which the radiosonde station is not located can be obtained.

However, there are two points worth noting about the proposed method. (a) From Eq. (1), only those data from the location of the radiosonde station were considered as being modelling data. For some cases, the established model may offer good accuracy because the atmospheric water vapour is relatively stable within a small research area (Rius et al., 1997); however, if the radiosonde station is located at the side of the area of interest, the accuracy of the established unit scale factor model may not be suitable for the whole tomography area and, even worse, the method proposed above cannot be used if the radiosonde data are unavailable or there are no radiosonde stations within the tomographic area. In addition, the temporal resolution of radiosonde data is low, as it is only obtained at 00:00 and 12:00 UTC. (b) It can be seen from Eq. (2) that only the elevation angle was considered in previous studies, which may not be able to reflect the characteristics of the unit scale factor in its entirety.

Therefore, the research here was designed to overcome such deficiencies. To solve the first problem, the data from the European Centre for Medium-Range Weather Forecasts were introduced: this can provide global reanalysis data for 
variables such as temperature and pressure. In our study, the modelling data derived from the radiosonde were replaced by the layered data derived from ECMWF with a minimum spatial resolution of $0.125^{\circ} \times 0.125^{\circ}$, while the temporal resolution was four times per day at 00:00, 06:00, 12:00, and 18:00 UTC, respectively. It can be observed from Fig. 1 that the ECMWF grid points are evenly distributed across the tomographic area, which will guarantee the accuracy of the unit scale factor model for the whole area. In addition, the temporal resolution is higher than that of the radiosonde data, the latter being obtained only twice a day. For the second issue, by analysing Eq. (1), we found that the unit scale factor was also subjected to SWV. In addition, the travel distances of SWV rays are different for different voxels. Therefore, the improved unit scale factor model is proposed and expressed as

$\gamma^{k}=a_{1}^{k}+a_{2}^{k} \cdot \sin (\mathrm{ele})+a_{3}^{k} \cdot\left(1 / \mathrm{SWV}^{p}\right)+a_{4}^{k} \cdot\left(1 / d_{i j k}^{p}\right)$,

where $a_{1}^{k}-a_{4}^{k}$ are the coefficients of unit scale factor model and $d_{i j k}^{p}$ is the distance of signal $p$ in voxel $(i, j, k)$.

For the satellite rays crossing from the top of the tomographic area, the observation equation can be expressed in linear form:

$\mathrm{SWV}=\sum d_{i j k} \cdot x_{i j k}$,

where $d_{i j k}$ is the distance travelled by the signal ray in voxel $(i, j, k)$, which can be calculated based on the intersections between the satellite ray and the two side faces of voxel $(i, j, k)$, and $x_{i j k}$ is the water vapour density of voxel $(i, j, k)$.

Although the signals coming out from the side of the research area were used, some voxels remained uncrossed by satellite rays due to the influence of the geometric distribution of receivers as well as the constellation of the GNSS satellites. Therefore, constraint conditions between the voxels for horizontal and vertical directions are still needed (Flores et al., 2000; Troller et al., 2002; Bender and Raabe, 2007). In our study, the Gauss-weighted function was used to describe the relationship of voxels aligned in a horizontal direction based on the knowledge that the water vapour density is relatively stable within a small area (Rius et al., 1997; Song et al., 2004). The empirical negative exponential function was exploited to restrict the values of voxels aligned in a vertical direction (Flores et al., 2000). Consequently, the final tomographic modelling of the improved method can be expressed as

$\left[\begin{array}{c}\boldsymbol{y}_{l_{1} \times 1} \\ \boldsymbol{\rho}_{l_{2} \times 1} \\ \mathbf{0}_{l_{3} \times 1} \\ \mathbf{0}_{l_{4} \times 1}\end{array}\right]=\left[\begin{array}{c}\boldsymbol{A}_{l_{1} \times n_{1}} \\ \boldsymbol{A} \boldsymbol{s}_{l_{2} \times n_{1}} \\ \boldsymbol{H}_{l_{3} \times n_{1}} \\ \boldsymbol{V}_{l_{4} \times n_{1}}\end{array}\right] \cdot \boldsymbol{X}_{n_{1} \times 1}$,

where $l_{1}-l_{4}$ are the number of observation equations, initial water vapour density equation, horizontal equation, and vertical equation, respectively; $n_{1}$ is the number of voxels in the

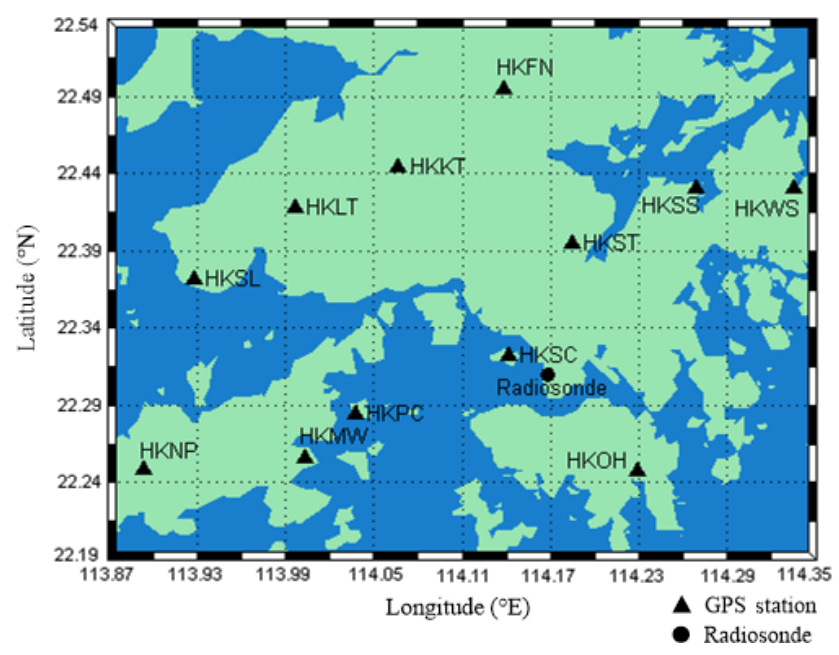

Figure 2. Geographic distribution of ground-based GPS, and radiosonde, stations in the research area.

tomography area; $\boldsymbol{H}$ and $\boldsymbol{V}$ are the coefficient matrices of horizontal and vertical constraints, respectively; and $\boldsymbol{A s}$ is the coefficient matrix representing the initial equation. The initial values which cannot be calculated in Eq. (3) are then set to a value of zero.

\section{Experiment and analysis}

\subsection{Experiment description and data-processing strategy}

The improved, proposed method was validated using the data from 12 stations (as shown by the black triangles in Fig. 2) from the Hong Kong Satellite Positioning Reference Station Network (SatRef) for the period of 25 March to 25 April 2014. The tomographic range is from 113.87 to 114.35 and 22.19 to 22.54 in longitude and latitude directions, respectively, while the tomography height is selected as $8 \mathrm{~km}$. The steps of longitude, latitude, and height are $0.06^{\circ}$, $0.05^{\circ}$, and $0.8 \mathrm{~km}$, respectively. Therefore, a total of $7 \times 8 \times 10$ voxels are discretised for the tomographic area. As shown by the black circle in Fig. 2, there is a radiosonde station (45004) located in the research area for which the sounding balloon is launched twice a day at 00:00 and 12:00 UTC, respectively. In addition, as shown by the black rectangles in Fig. 1, there are 12 ECMWF grid points evenly distributed in the area of interest: further geographical information is given in Table 1.

In the present study, the GPS data were processed using GAMIT/GLOBK (v. 10.5) (Herring et al., 2010) software at a sampling interval of $30 \mathrm{~s}$. The wet Niell mapping function was used (Niell, 1996) to project the SWD. The intervals of zenith total delay (ZTD) and wet horizontal gradients were estimated as being 0.5 and $2 \mathrm{~h}$, respectively. To obtain the absolute tropospheric parameters, three International GNSS Service (IGS) stations (SHAO, LHAZ, and BJFS) were also 
Table 1. Geographic coordination of ECMWF grid points located in the research area.

\begin{tabular}{lrr|lrr}
\hline Number & Longitude $\left(^{\circ}\right)$ & Latitude $\left(^{\circ}\right)$ & Number & Longitude $\left({ }^{\circ}\right)$ & Latitude $\left(^{\circ}\right)$ \\
\hline B1L1 & 113.875 & 22.250 & B2L3 & 114.125 & 22.375 \\
B1L2 & 114.000 & 22.250 & B2L4 & 114.250 & 22.375 \\
B1L3 & 114.125 & 22.250 & B3L1 & 113.875 & 22.500 \\
B1L4 & 114.250 & 22.250 & B3L2 & 114.000 & 22.500 \\
B2L1 & 113.875 & 22.375 & B3L3 & 114.125 & 22.500 \\
B2L2 & 114.000 & 22.375 & B3L4 & 114.250 & 22.500 \\
\hline
\end{tabular}

used in GPS data resolution (Rocken et al., 1995; Yao and Zhao, 2016). During the conversion from SWD to SWV (Bevis et al., 1992), the weighted mean tropospheric temperature was calculated based on the empirical formula proposed by Chen et al. (2007) using the observed surface temperature.

To compare the performance of the improved method, three methods are used in this tomographic modelling.

Method 1: only using the signals penetrating from the top of research area to build the observation equation, and superimposing the horizontal and vertical equations mentioned in Sect. 2.

Method 2: apart from the tomographic modelling established by method 1 , the signals crossing from the side face of the tomographic area were also used with the old unit scale factor model established from radiosonde data to build the initial equation.

Method 3: apart from the tomographic modelling established by method 1 , the signals crossing from the side face of the tomographic area were also used with the new unit scale factor model established in this paper based on ECMWF grid points data to build the initial equation.

\subsection{Analysis of the new unit scale factor model}

It can be seen from Figs. 3 and 4 that the number of signals used and the number of voxels crossed by satellite rays are the same for methods 2 and 3, while that for method 1 is relatively small for the tested period, with an interval of $30 \mathrm{~min}$ used throughout. When the signals crossing the side face of the area were used, the signal utilisation rate was increased by $32.84 \%$, while the number of voxels traversed by rays was improved by $14.09 \%$, from 64.65 to $78.74 \%$. However, by comparing the number of initial water vapour density values (see Fig. 5) which we can calculate for methods 2 and 3, we found that the number of initial values calculated of water vapour density from method 2 is less than that of method 3 . This is because not all the unit scale factor model data can be established for every layer of the tomographic area based on the old model using radiosonde data. However, the improved method enabled the new unit scale factor model to be estab-

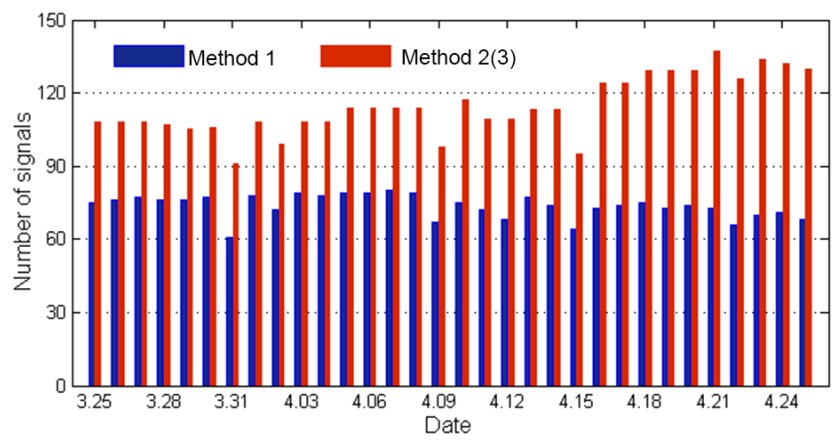

Figure 3. The number of signals used for different methods in the experiment.

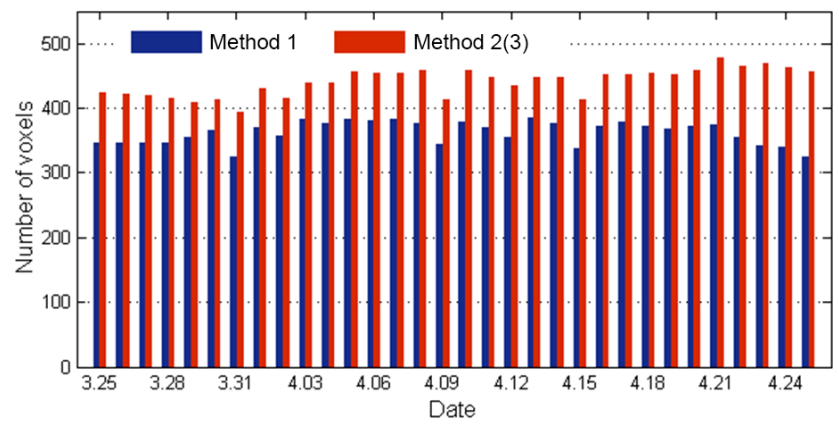

Figure 4. The number of voxels crossed by rays for different methods in the experiment.

lished for every layer by using the data from ECMWF grid points.

To validate further the new unit scale factor model, a comparison of the accuracy comparison of methods 2 and 3 was performed below. On the one hand, the RMS errors in water vapour density differences derived from the old/new unit scale factor mode established above and radiosonde/ECMWF data used to build the unit scale model were calculated to evaluate the internal accuracy of the two models. On the other hand, the external accuracies of two models were also calculated, the initial water vapour density values calculated from the old unit scale factor model was compared with that from radiosonde data of the tomographic epoch at 00:00 and 12:00 UTC every day, while the new unit scale factor model was compared with that from ECMWF 


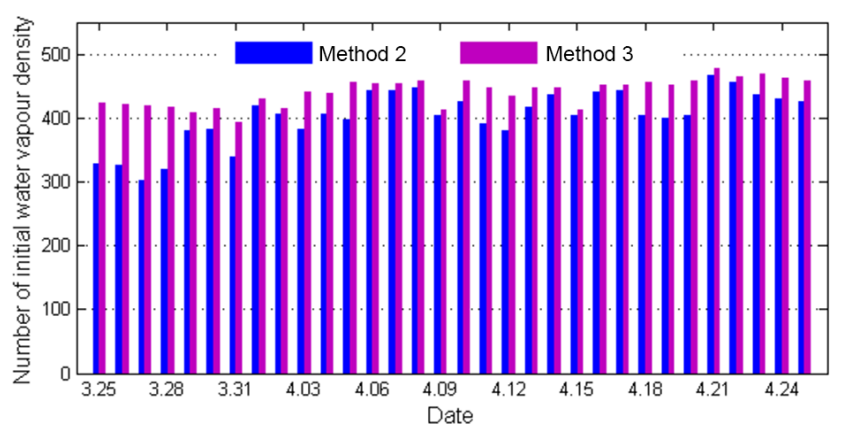

Figure 5. The number of initial water vapour density values derived from methods 2 and 3 in the experiment.

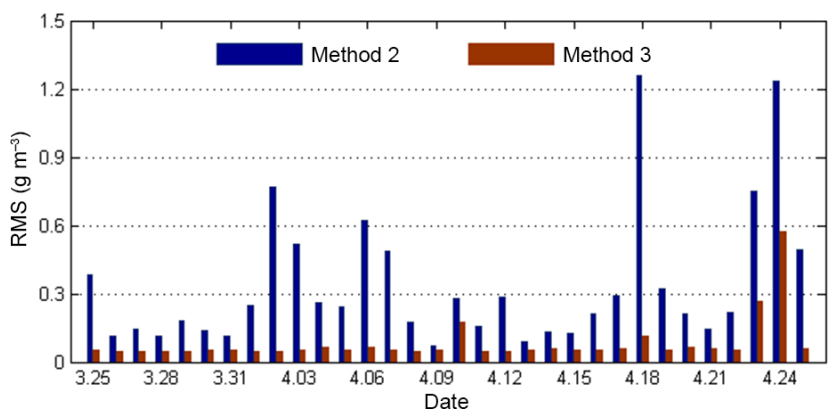

Figure 6. Internal accuracy of the unit scale factor models used for methods 2 and 3 in the experiment.

data of the tomographic epoch at 00:00, 06:00, 12:00, and 18:00 UTC on each day. Figures 6 and 7 show the internal accuracy and external accuracy for both unit scale factor models used in methods 2 and 3 throughout the experiment. It can be seen that the new unit scale factor model of the improved method has a higher internal/external accuracy than that of the old unit scale factor model in the previous study. Numerical results show that the average RMS errors of internal/external accuracy for the old/new unit scale factor models were $0.34 / 0.08$ and $1.64 / 0.24 \mathrm{~g} \mathrm{~m}^{-3}$, respectively. Table 2 lists the statistical result of accuracy evaluation for the old/new unit scale factor models.

\subsection{Comparison with water vapour information derived from the radiosonde}

As mentioned by previous studies, the radiosonde can provide accurate water vapour density profiles at different altitudes (Niell, 2001; Adeyemi and Joerg, 2012; Liu et al., 2013), which makes it suitable for use as a reference against which to assess the accuracy of the tomographic result. The integrated water vapour (IWV) value for the location of the radiosonde station was calculated using the water vapour density of voxels derived from different tomographic results and compared with that from the radiosonde data at 00:00 and 12:00 UTC, respectively. It can be seen (Fig. 8) that the IWV time series derived from the three tomographic meth-

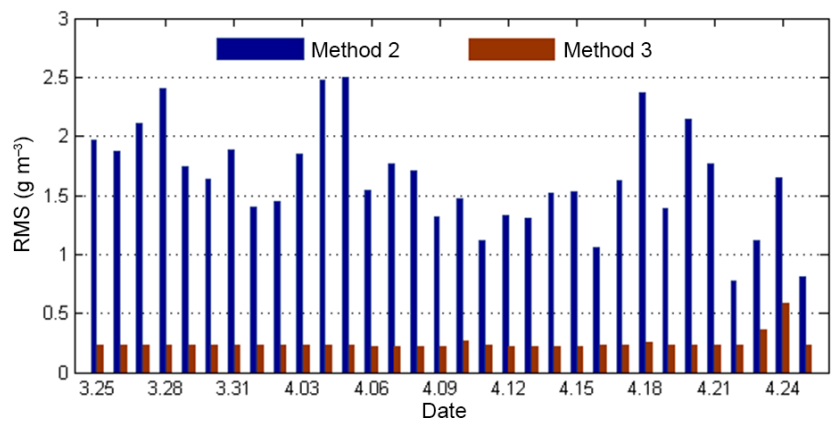

Figure 7. External accuracy of the unit scale factor models used for methods 2 and 3 in the experiment.

Table 2. Statistical result of RMS error for the old/new unit scale factor models used by the conventional and improved methods in the experiment $\left(\mathrm{g} \mathrm{m}^{-3}\right)$.

\begin{tabular}{lccc|ccc}
\hline \multirow{2}{*}{ Method } & \multicolumn{2}{c|}{ Internal accuracy } & \multicolumn{3}{c}{ External accuracy } \\
\cline { 2 - 7 } & Mean & Max & Min & Mean & Max & Min \\
\hline 2 & 0.34 & 1.26 & 0.07 & 1.64 & 2.50 & 0.78 \\
3 & 0.08 & 0.57 & 0.04 & 0.24 & 0.58 & 0.22 \\
\hline
\end{tabular}

ods matched the radiosonde data. The statistical results from the experimental period revealed that the RMS/mean absolute error (MAE)/bias values for three tomographic methods were 5.82/3.42/4.95, 5.02/2.40/4.16, and 4.91/2.62/4.13 mm, respectively.

The water vapour density profile for the location of radiosonde was analysed for heights of up to $5 \mathrm{~km}$ because the largest atmospheric water vapour content is included in this height range. Figure 9 shows the RMS error and MAE of water vapour density differences between radiosonde and different tomographic methods: the accuracies of methods 2 and 3 are superior to that of method 1, which is because more observed data points were imposed onto the tomographic model. Table 3 also lists the statistical results of RMS, MAE, and bias for the three tomographic methods. The numerical results show that the RMS/MAE/bias values of the three tomographic methods were $2.48 / 2.01 /-0.18,2.24 / 1.81 /-0.16$, and $1.67 / 1.34 /-0.11 \mathrm{~g} \mathrm{~m}^{-3}$, respectively.

In addition, the water vapour density profile comparison was also compared again for heights of up to $8 \mathrm{~km}$. Figures 10 and 11 show the histograms of RMS and MAE for the three tomographic methods used. Table 4 lists the statistical results (RMS, MAE, and bias) for the three tomographic methods. It can be seen from Figs. 10 and 11 that the accuracy of the improved method is the best, while that of method 2 was second best, thus showing that the new unit scale factor model of the improved method is better than the old model used by method 2. Numerical results reveal that the RMS/MAE/bias values for the three to- 


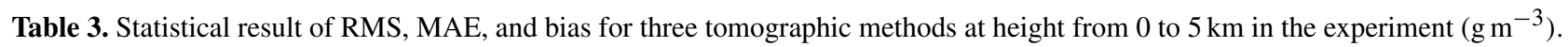

\begin{tabular}{lccc|ccc|ccc}
\hline \multirow{2}{*}{ Method } & \multicolumn{3}{c|}{ RMS } & \multicolumn{3}{c|}{ MAE } & \multicolumn{3}{c}{ Bias } \\
\cline { 2 - 9 } & Mean & Max & Min & Mean & Max & Min & Mean & Max & Min \\
\hline 1 & 2.48 & 4.79 & 1.05 & 2.01 & 3.76 & 0.83 & -0.18 & 0.93 & -0.86 \\
2 & 2.24 & 4.62 & 0.93 & 1.81 & 7.70 & 0.73 & -0.16 & 0.87 & -0.80 \\
3 & 1.67 & 4.13 & 0.26 & 1.34 & 3.44 & 0.20 & -0.11 & 0.81 & -0.76 \\
\hline
\end{tabular}

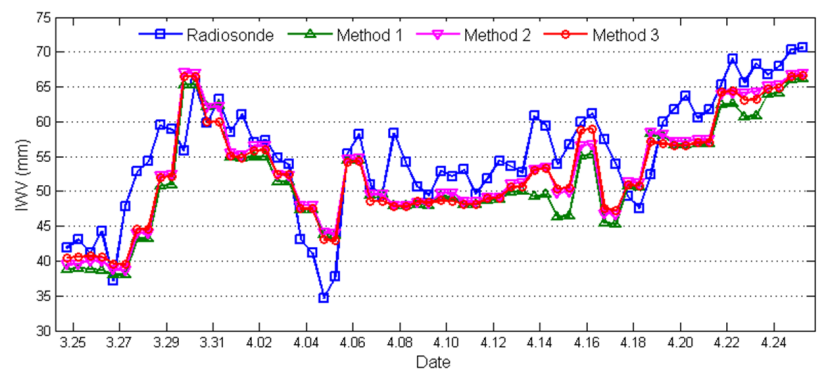

Figure 8. Comparison of IWV time series derived from radiosonde and different tomographic methods in the experiment.
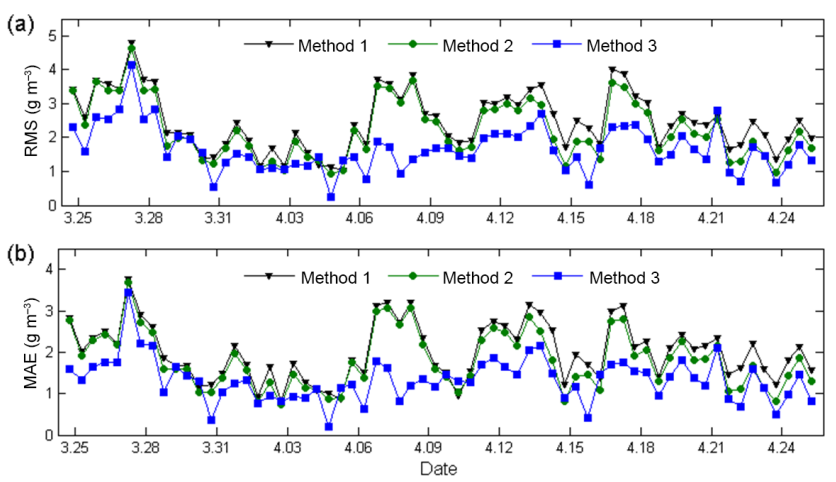

Figure 9. RMS error and MAE of water vapour density differences between radiosonde and three tomographic methods in the experiment.

mographic methods were $1.79 / 1.16 /-0.77,1.61 / 1.04 /-0.53$, and $1.19 / 0.76 /-0.26 \mathrm{~g} \mathrm{~m}^{-3}$, respectively.

The water vapour density profiles at different altitudes were also compared to investigate the relationship between the different tomographic model errors and height. The average RMS error and relative error at different layers for three tomographic models were calculated for the period from 25 March to 25 April 2014. Fig. 12 shows the RMS and relative error changes with height throughout the experimental period. It can be seen from Fig. 12 that the RMS error, in general, decreased with altitude, while the relative error showed the opposite trend. The RMS error and relative error of the improved method, in general, were smaller than those of methods 1 and 2, which also demonstrated that the new

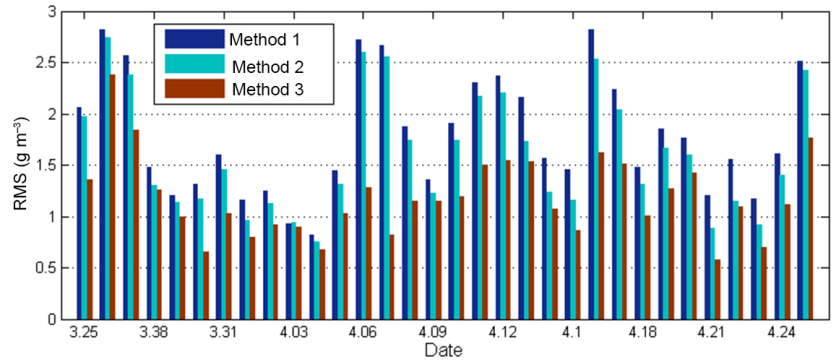

Figure 10. Histogram of RMS error for different tomographic areas in the experiment.

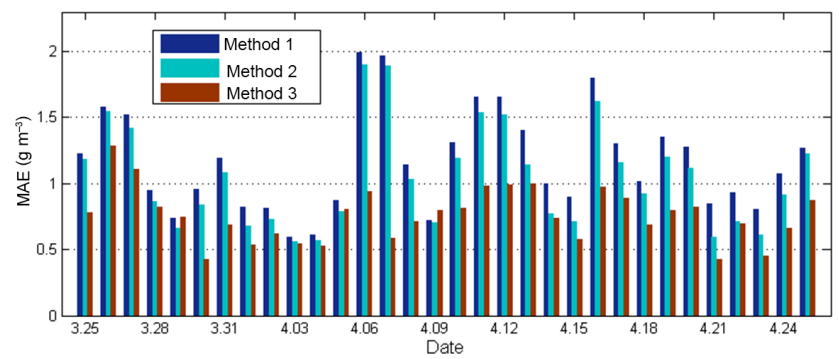

Figure 11. Histogram of MAE for different tomographic areas in the experiment.
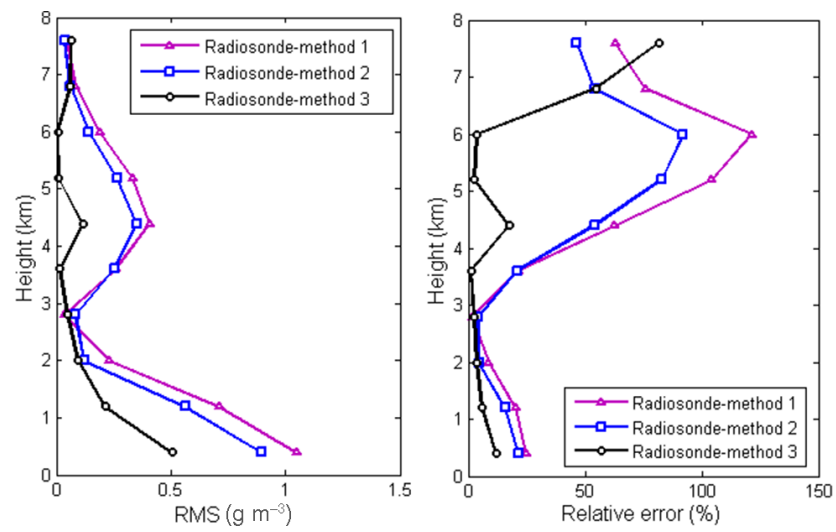

Figure 12. RMS and relative error change with height for three tomographic methods from 25 March to 25 April 2014. 
Table 4. Statistical result of RMS, MAE, and bias for three tomographic methods at heights from 0 to $8 \mathrm{~km}$ in the experiment $\left(\mathrm{g} \mathrm{m}^{-3}\right)$.

\begin{tabular}{lrcc|ccc|ccc}
\hline \multirow{2}{*}{ Method } & \multicolumn{3}{c|}{ RMS } & \multicolumn{3}{c|}{ MAE } & \multicolumn{3}{c}{ Bias } \\
\cline { 2 - 10 } & Mean & Max & Min & Mean & Max & Min & Mean & Max & Min \\
\hline 1 & 1.79 & 2.82 & 0.82 & 1.16 & 2.00 & 0.59 & -0.77 & 2.20 & -2.54 \\
2 & 1.61 & 2.75 & 0.75 & 1.04 & 1.90 & 0.56 & -0.53 & 2.13 & -2.48 \\
3 & 1.19 & 2.39 & 0.58 & 0.76 & 1.28 & 0.42 & -0.26 & 1.72 & -1.74 \\
\hline
\end{tabular}

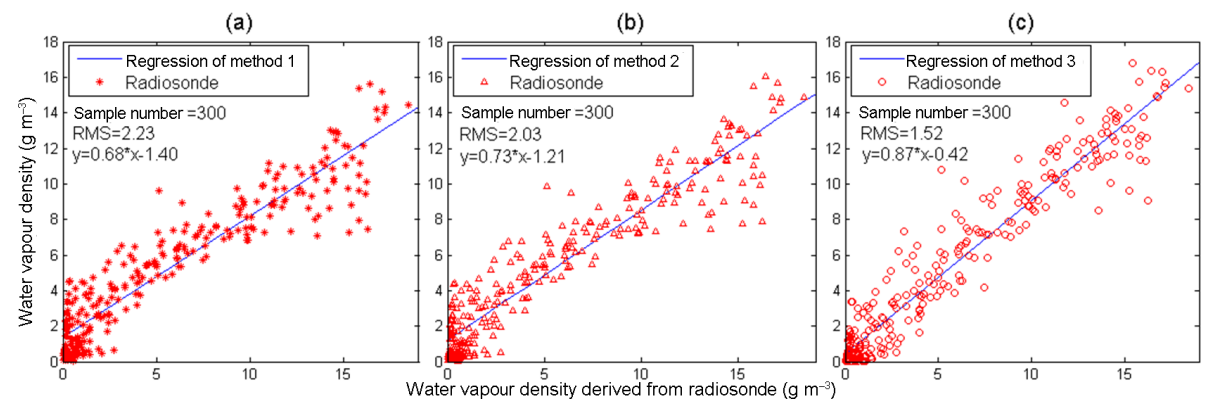

Figure 13. Linear regression of water vapour density derived from radiosonde and three tomography methods in the experiment.

unit scale factor model in the improved method was superior to the previous version.

The water vapour density values were sampled randomly over the test period of 32 days and then compared with values calculated using radiosonde data. In our study, 300 sampled values were determined for each of the three tomographic methods. Figure 13 shows the linear regression on the water vapour density for the three methods. From the sampled data it may be concluded that the improved method proposed in this paper showed the best regression result compared to that of methods 1 and 2 . The RMS errors of water vapour density differences of method 1-radiosonde, method 2-radiosonde, and method 3-radiosonde for the sampled data were 2.23, 2.03 , and $1.52 \mathrm{~g} \mathrm{~m}^{-3}$, respectively.

\section{Conclusions}

A new unit scale factor model was proposed using the layered data provided by ECMWF, which considered the reasonability of selecting modelling data as well as the modelling parameters. We analysed the accuracy of this new unit scale factor model and validated the tomographic result of the improved method. The GPS observations from 12 stations forming the Hong Kong Satellite Positioning Reference Station Network were used for the period of 25 March to 25 April 2014. By analysing the initial water vapour density values, which were calculated by the unit scale factor model, we found that the new model proposed in this paper enhanced the number of initial values estimated by $6.83 \%$. The internal/external accuracies of the new unit scale factor model were analysed: the new model was superior to the model used in a previous study. Comparing the IWV time series with that from radiosonde data, it was found that the RMS, MAE, and bias of the improved method were 4.91, 2.62, and $4.13 \mathrm{~mm}$, respectively, which were smaller than those of previous methods. The statistical results of water vapour density between radiosonde and different tomographic methods over the 32-day test period also showed that the improved method offered an improved performance. In addition, the RMS error and relative error showed completely opposite trends with changing height.

Overall, the improved tomography method using the new unit scale factor model has enhanced the accuracy of tomographic result by 33.5 and $26.1 \%$, respectively, when compared to the previous studies (methods 1 and 2). With the continuous improvement of the GNSS network, more satellite signals will be used and more voxels will be crossed by rays. Furthermore, some other observations derived from interferometric synthetic aperture radar (InSAR) or COSMIC radio occultation data can also be used for the troposphere tomography, either directly or indirectly. It is expected that tropospheric tomography with higher-quality water vapour information will be obtained in the near future.

\section{Data availability}

The GPS observation and meteorological data can be download from the Lands Department of HKSAR (https://www. geodetic.gov.hk/smo/index.htm). The radiosonde data sets and ECMWF grid data sets are available from the websites of ftp://ftp.ncdc.noaa.gov/pub/data/igra/ and http://apps.ecmwf. int/datasets/, respectively. 
Acknowledgements. The authors would like to thank IGAR and ECMWF for providing access to the web-based IGAR and layered meteorological data. The Lands Department of HKSAR is also acknowledge for providing GPS data from the Hong Kong Satellite Positioning Reference Station Network (SatRef). This research was supported by the National Key Research and Development Program of China (2016YFB0501803) and the National Natural Science Foundation of China (41574028).

The topical editor, M. Salzmann, thanks J. Bosy and one anonymous referee for help in evaluating this paper.

\section{References}

Adeyemi, B. and Joerg, S.: Analysis of water vapor over Nigeria using radiosonde and satellite data, J. Appl. Meteorol. Clim., 51, 1855-1866, 2012.

Bauer, H. S., Wulfmeyer, V., Schwitalla, T., Zus, F., and Grzeschik, M.: Operational assimilation of GPS slant path delay measurement into the MM5 4DVAR system, Tellus A, 63, 263-282, 2011.

Bender, M. and Raabe, A.: Preconditions to ground based GPS water vapour tomography, Ann. Geophys., 25, 1727-1734, doi:10.5194/angeo-25-1727-2007, 2007.

Benevides, P., Catalão, J., and Miranda, P. M.: Experimental GNSS tomography study in Lisbon (Portugal), Física de la Tierra, 26, 65-79, 2014.

Benevides, P., Nico, G., Catalao, J., and Miranda, P.: Merging SAR interferometry and GPS tomography for high-resolution mapping of 3D tropospheric water vapour, Int. Geosci. Remote. Se., 3607-3610, 2015.

Bevis, M., Businger, S., Herring, T. A., Rocken, C., Anthes, R. A., and Ware, R. H.: GPS meteorology: Remote sensing of atmospheric water vapor using the Global Positioning System, J. Geophys. Res.-Atmos., 97, 15787-15801, 1992.

Braun, J., Rocken, C., Meertens, C., and Ware, R.: Development of a water vapor tomography system using low cost L1 GPS receivers, 9th ARM Science Team Meeting, US Dep. of Energy, San Antonio, Texas, 22-26, March, 1999.

Brenot, H., Walpersdorf, A., Reverdy, M., van Baelen, J., Ducrocq, V., Champollion, C., Masson, F., Doerflinger, E., Collard, P., and Giroux, P.: A GPS network for tropospheric tomography in the framework of the Mediterranean hydrometeorological observatory Cévennes-Vivarais (southeastern France), Atmos. Meas. Tech., 7, 553-578, doi:10.5194/amt-7-553-2014, 2014.

Chen, B. and Liu, Z.: Assessing the performance of troposphere tomographic modeling using multi-source water vapor data during Hong Kong's rainy season from May to October 2013, Atmos. Meas. Tech., 9, 5249-5263, doi:10.5194/amt-9-5249-2016, 2016.

Chen, Y. Q., Liu, Y. X., Wang, X. Y., and Li, P. H.: GPS real-time estimation of precipitable water vapor-Hong Kong experiences, Acta Geod. Cartogr. Sin., 36, 9-12, 2007.

Douša , J. and Vaclavovic, P.: Real-time zenith tropospheric delays in support of numerical weather prediction applications, Adv. Space Res., 53, 1347-1358, 2014.

Douša, J., Dick, G., Kacmarík, M., Brožková, R., Zus, F., Brenot, H., Stoycheva, A., Möller, G., and Kaplon, J.: Benchmark campaign and case study episode in central Europe for development and assessment of advanced GNSS tropospheric models and products, Atmos. Meas. Tech., 9, 2989-3008, doi:10.5194/amt9-2989-2016, 2016.

Ducroco, V., Ricard, D., Lafore, J. P., and Orain, F.: Storm-scale numerical rainfall prediction for five precipitable events over France: on the importance of the initial humidity field, Weather Forecast., 17, 1236-1256, 2002.

Emanuel, K., Raymond, D., Betts, A., Bosart, L., Bretherton, C., Droegemeir, K., Farrell, B., Fritsch, J. M., Houze, R., Lily, D., Shapiro, M., Smith, R., and Thorpe, A.: Report of the first Prospectus Development Team of the U.S. Weather Research Program to NOAA and the NSF, B. Am. Meteorol. Soc., 76, 1194-1208, 1995.

Flores, A., Ruffini, G., and Rius, A.: 4D tropospheric tomography using GPS slant wet delays, Ann. Geophys., 18, 223-234, doi:10.1007/s00585-000-0223-7, 2000.

Herring, T. A., King, R. W., and McClusky, S. C.: Documentation of the GAMIT GPS Analysis Software release 10.4., Department of Earth and Planetary Sciences, Massachusetts Institute of Technology, Cambridge, Massachusetts, 2010.

Heublein, M., Zhu, X. X., Alshawaf, F., Mayer, M., Bamler, R., and Hinz, S.: Compressive sensing for neutrospheric water vapor tomography using GNSS and InSAR observations, Int. Geosci. Remote. Se., 5268-5271, 2015.

Liu, J., Sun, Z., Liang, H., Xu, X., and Wu, P.: Precipitable water vapor on the Tibetan Plateau estimated by GPS, water vapor radiometer, radiosonde, and numerical weather prediction analysis and its impact on the radiation budget, J. Geophys. Res.-Atmos., 110, 1-12, 2005.

Liu, Z., Man, S. W., Nichol, J., and Chan, P. W.: A multi-sensor study of water vapour from radiosonde, modis and aeronet: a case study of hong kong, Int. J. Climatol., 33, 109-120, 2013.

Niell, A. E.: Global mapping functions for the atmosphere delay at radio wavelengths, J. Geophys. Res.-Sol. Ea., 101, 3227-3246, 1996.

Niell, A. E.: Comparison of measurements of atmospheric wet delay by radiosonde, water vapor radiometer, gps, and vlbi, J. Atmos. Ocean. Tech., 18, 830-850, 2001.

Nilsson, T. and Gradinarsky, L.: Water vapor tomography using GPS phase observations: simulation results, IEEE T. Geosci. Remote Sens., 44, 2927-2941, 2006.

Notarpietro, R., Cucca, M., Gabella, M., Venuti, G., and Perona, G.: Tomographic reconstruction of wet and total refractivity fields from GNSS receiver networks, Adv. Space Res., 47, 898-912, 2011.

Park, S. K.: Nonlinearity and predictability of convective rainfall associated with water vapor perturbations in a numerically simulated storm, J. Geophys. Res., 104, 31575-31587, 1999.

Perler, D., Geiger, A., and Hurter, F.: 4D GPS water vapor tomography: new parameterized approaches, J. Geodesy, 85, 539-550, 2011.

Rius, A., Ruffini, G., and Cucurull, L.: Improving the vertical resolution of ionospheric tomography with GPS occultations, Geophys. Res. Lett., 24, 2291-2294, 1997.

Rius, A., Ruffini, G., and Cucurull, L.: Improving the vertical resolution of ionospheric tomography with GPS occultations, Geophys. Res. Lett., 24, 2291-2294, 1997.

Rocken, C., Hove, T. V., Johnson, J., Solheim, F., Ware, R., Bevis, M., and Businger, S.: GPS/STORM-GPS sensing of atmospheric 
water vapor for meteorology, J. Atmos. Ocean. Tech., 12, 468478, 1995.

Skone, S. and Hoyle, V.: Troposphere modeling in a regional GPS network, J. Global Positioning System, 4, 230-239, 2005.

Song, S.: Sensing three dimensional water vapor structure with ground-based GPS network and the application in meteorology, $\mathrm{PhD}$ dissertation, Shanghai Astron. Obs., Shanghai, China, 6, 85-93, 2004.

Troller, M., Bürki, B., Cocard, M., Geiger, A., and Kahle, H. G.: 3 -D refractivity field from GPS double difference tomography, Geophys. Res. Lett., 29, 2-1-2-4, 2002.

Wang, X., Wang, X., Dai, Z., Ke, F., Cao, Y., Wang, F., and Song, L.: Tropospheric wet refractivity tomography based on the BeiDou satellite system, Adv. Atmos. Sci., 31, 355-362, 2014.
Wilgan, K., Hurter, F., Geiger, A., Rohm, W., and Bosy, J.: Tropospheric refractivity and zenith path delays from least-squares collocation of meteorological and GNSS data, J. Geodesy, 1-18, 2016.

Xia, P., Cai, C., and Liu, Z.: GNSS troposphere tomography based on two-step reconstructions using GPS observations and COSMIC profiles, Ann. Geophys., 31, 1805-1815, doi:10.5194/angeo-31-1805-2013, 2013.

Yao, Y. and Zhao, Q.: A novel, optimized approach of voxel division for water vapor tomography, Meteorol. Atmos. Phys., 1-14, 2016.

Yao, Y. B., Zhao, Q. Z., and Zhang, B.: A method to improve the utilization of GNSS observation for water vapor tomography, Ann. Geophys., 34, 143-152, doi:10.5194/angeo-34-143-2016, 2016. 